AperTO - Archivio Istituzionale Open Access dell'Università di Torino

\title{
Comparison of limit-equilibrium, numerical and physical models of wall slope stability
}

\section{This is the author's manuscript}

Original Citation:

Availability:

This version is available http://hdl.handle.net/2318/127329

since

Published version:

DOI:10.1016/j.jijmms.2010.06.013

Terms of use:

Open Access

Anyone can freely access the full text of works made available as "Open Access". Works made available under a Creative Commons license can be used according to the terms and conditions of said license. Use of all other works requires consent of the right holder (author or publisher) if not exempted from copyright protection by the applicable law. 


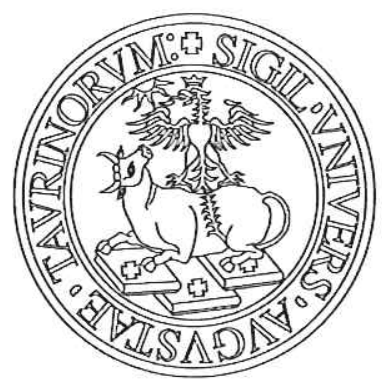

\section{UNIVERSITÀ DEGLI STUDI DI TORINO}

This is an author version of the contribution published on:

Questa è la versione dell'autore dell'opera:

Alejano L., Ferrero A.M. P. Ramírez-Oyanguren, M.I. Álvarez Fernández (2011) Stability of wall slopes: limit equilibrium, numerical and physical models Int. J. Rock Mech. \& Geomech. Abs. 48 16-26 doi:10.1016/j.jirmms.2010.06.013

The definitive version is available at:

La versione definitiva è disponibile alla URL:

http://ac.els-cdn.com/S1365160910001103/1-s2.0-S1365160910001103main.pdf?_tid=27985f52-aa86-11e3-a3a6-

00000aacb35f\&acdnat=1394698071_7a2df38bee03fe404fab42db8154c2df 


\title{
Stability of wall slopes: limit equilibrium, numerical and physical models
}

\author{
L.R. Alejano ${ }^{1}$, A.M. Ferrero ${ }^{2}$, P. Ramírez-Oyanguren ${ }^{3}$ \& M.I. Álvarez Fernández ${ }^{4}$ \\ ${ }^{1}$ Department of Natural Resources \& Environmental Engineering, University of Vigo, Spain \\ ${ }^{2}$ Department of Civil, Environmental, Land Engineering \& Architecture, University of Parma, Italy \\ ${ }^{3}$ Department of Mineral Resources Exploitation \& Underground Works, Polytechnic University of Madrid, Spain \\ ${ }^{4}$ Department of Mining Engineering, University of Oviedo, Spain
} ${ }^{1}$ Corresponding author, School of Mines, Campus Lagoas s/n, 36.310, Vigo (Pontevedra), E-36.310
España. Phone : +34 9868123 74, Fax: +34 98681 19 24, e-mail: alejano@uvigo.es

\section{Summary}

In this paper the commonly observed failure mechanisms associated to footwall slopes are reviewed and the basic concepts of the Limit Equilibrium Methods (LEM) to assess their stability are recalled. The cases presented include those with failure mechanisms following only pre-existing joints and examples where failure takes place mainly along discontinuities but also through intact rock. Various numerical models performed with the code UDEC are also shown to illustrate the potential of the code to analyze these failures. Moreover, some physical models of these types of instability have been reproduced in a tilt test set-up in the laboratory. These empirical results compare fairly well with the theoretical approaches.

Key words: Rock engineering, slope stability analyses, Wall slope, UDEC, physical modelling.

\section{INTRODUCTION}

Surface mining of coal often involves the formation of extensive footwall slopes parallel to strata dip (Fig. 1). In these circumstances a detailed study of the stability is needed. These instability mechanisms are not very often considered in classic civil or mining rock slope design techniques. However, they have produced some important accidents in mines (Coulthard et al; 2004). They are mainly linked to the sliding of a mass of rock through one of these pre-existing discontinuities, but they also need either one or more smaller discontinuities, or the yield of an area of intact rock due to compressive, shear or tensile stress to allow the coming out of the sliding material. Studies of stability of this type of slopes in various mines have shown that certainly different mechanism may arise (Walton \& Atkinson, 1978; Cavers, 1981; Hawley et al, 1986; Stead \& Eberhardt, 1997; Manera-Basa \& Ramírez-Oyanguren, 1986). 


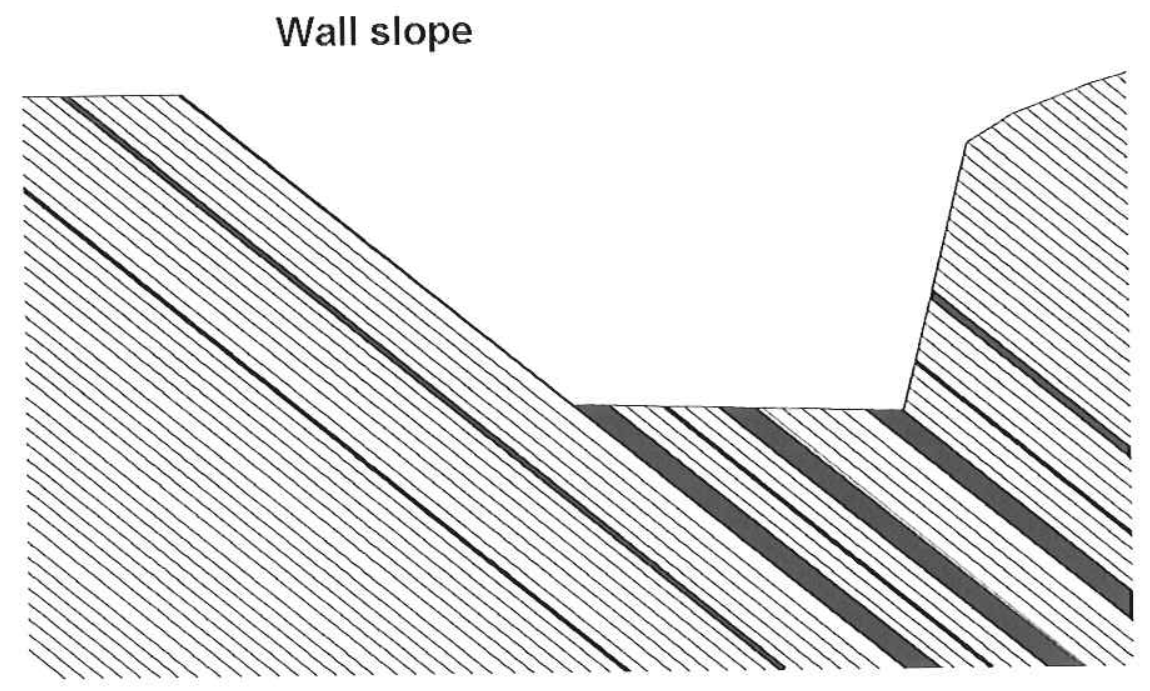

Figure 1. Typical footwall slope where the instabilities analysed here may take place.

Moreover it has been found that some of this mechanisms are not only prone to occur in surface coal mining, but they can also be encountered in mines and slopes where instability is structurally controlled, typically by a joint set, fault, or weak zone parallel or sub-parallel to the slope. See for instance the complex failure occurred at Brenda Mines associated to metal mining (Calder \& Blackwell (1980). Account also for the stability analysis of a limestone quarry and a quartz mine reported by the first author of this paper (Alejano et al, 2001). Therefore, the occurrence of these footwall slope instabilities is probably more common than it seems to. In Figure 2, illustrations of four Spanish mining and road slopes, which have suffered these problems are presented.

In their detailed work Stead \& Eberhardt (1997), reviewed the factors influencing footwall slope stability in surface coal mining and the major instability mechanisms reported in literature. They also introduce the numerical approach to analyse these phenomena.

Probably the first technical document dealing with this topic is that by Brawner et al. (1971) proposing limit equilibrium methods (LEM) of analysis of bilinear slab failures. Hawley et al. (1987), for different types, and Cavers (1981), for the case of buckling, proposed more detailed limit equilibrium approaches. However, Hawley et al. (1987) presented solutions to estimate the artificial support needed at the toe, instead of providing a factor of safety. Alejano (2004) also presented a LEM and numerical approach to the topic, but some small errata have been detected in this work, so this paper can be considered an improvement and extension of that publication. 

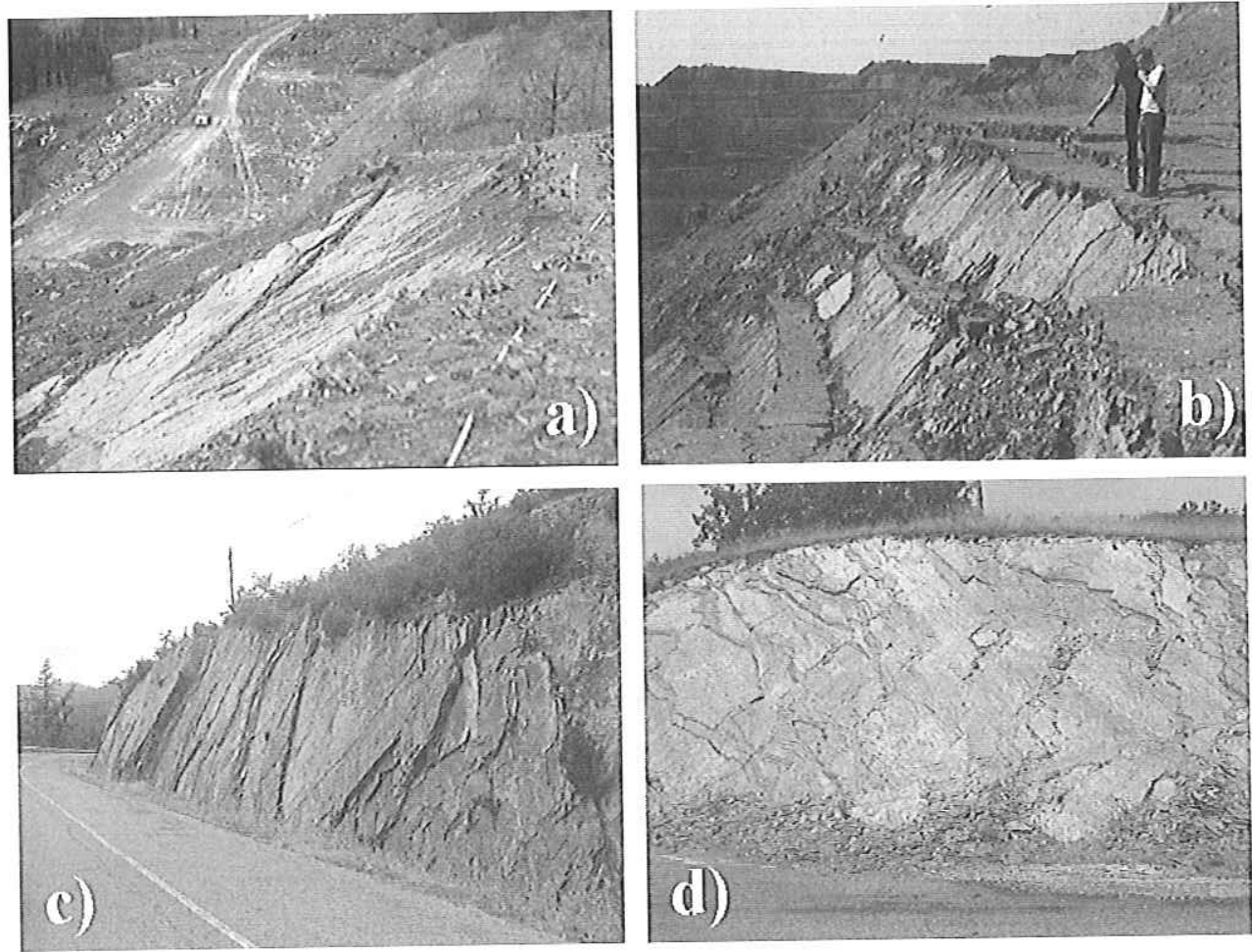

Figure 2. Pictures of four slopes, where footwall slope instability is detected. a) Road works in flysch material in northern Spain, b) coal mines in Southern Spain, c \& d) Roads in slates in central Spain.

For the case of bilinear slab failure analysis, LEM are proposes assuming that the boundary between the active and passive blocks is either frictionless (Brawner, 1971; Stimpson \& Robinson; 1981), or accounting for the effect of friction (Hawley et al, 1987). Therefore numerical and physical models as presented in this text, which can be an interesting approach to study the reliability of theses assumptions in practice.

In the study of footwall slopes, the code UDEC (Itasca, 2001) has shown to be a useful tool to understand the mechanism associated with these phenomena and to calculate the safety factor of the designed footwall slope, based on the shear strength reduction technique (Dawson et al., 1999).

Sometimes those mechanisms occurred not only following existing joints, but crushing, shearing or tensioning the rock. In this cases LEM need assumptions on the geometry of the failure surface to be studied, and therefore cases can be more reliably studied by means of numerical approaches.

Within this general picture, we present in this work a brief revision of the failure mechanisms associated to footwall slope failure. We later describe the LEM and numerical approaches to obtain factors of safety $(\mathrm{FoS})$ for the cases of bilinear slab and ploughing slab failure. And finally we show a series of physical models performed in our laboratory, which have served to check the reliability of the previous approaches, which can be used in practice and to put forward their pros and cons. Although it was planed to introduce some cases studies in which the authors were involved and some 
recovered from literature, it was decided to leave that topic for a further publication, due to the actual length of the paper. Nevertheless, we strongly recommend the reader to go through the references given to get acquaintance with some actual case studies.

\section{FAILURE MECHANISMS}

\subsection{Review of failure mechanisms}

High slope with persistent discontinuities parallel to its face are prone to fail according to different mechanisms reviewed by Hawley et al. (1985) and that can be primarily divided according to the full or partial discontinuity control.

If the failure mechanism is totally controlled by pre-existing discontinuities the instability phenomena presented in the next section may take place. Planar failure is not considered, for it has been sufficiently studied (Hoek \& Bray, 1973; Kliche, 1999).

If no secondary joints enabling instability exist, then, the discontinuity control is only partial and the failure phenomena necessitate the crushing or shearing of the rock mass. The instability mechanisms resulting in this case - presented in section 2.3- are geometrically similar to the previously mentioned ones, but they are obviously less likely to occur.

\subsection{Totally joint controlled failure mechanisms}

The most commonly encountered mechanisms, presented in Figure 3 include:

a) Bilinear slab failure, which involves sliding along a basal plane in combination with sliding along a secondary shallow dipping joint, which is undercut by the slope face (Fig. 3.A). Hawley et al. (1985) reported this type of failure in a mine.

b) Ploughing slab failure, which takes place when slab sliding along a primary discontinuity combines with sliding along a joint, which strikes sub-parallel to the slope face, causing the toe block to be lifted by sliding and eventually rotated out of the slope (Fig. 3.B). Although this mechanism seems to be not very common Manera-Bassa \& Ramírez-Oyanguren (1986) and Calder \& Blackwell (1980) reported particular cases of this type of instability mechanism.

c) Three hinge buckling, described by Cavers (1981), is the third known mechanism of this type. It assumes the presence of at least three joints normal to bedding in the slope's lower part. Failure is initiated when enough water pressure exists in the basal plane to induce rotation or shearing along cross-joints causing the extrusion of blocks. (Fig. 3.C). 


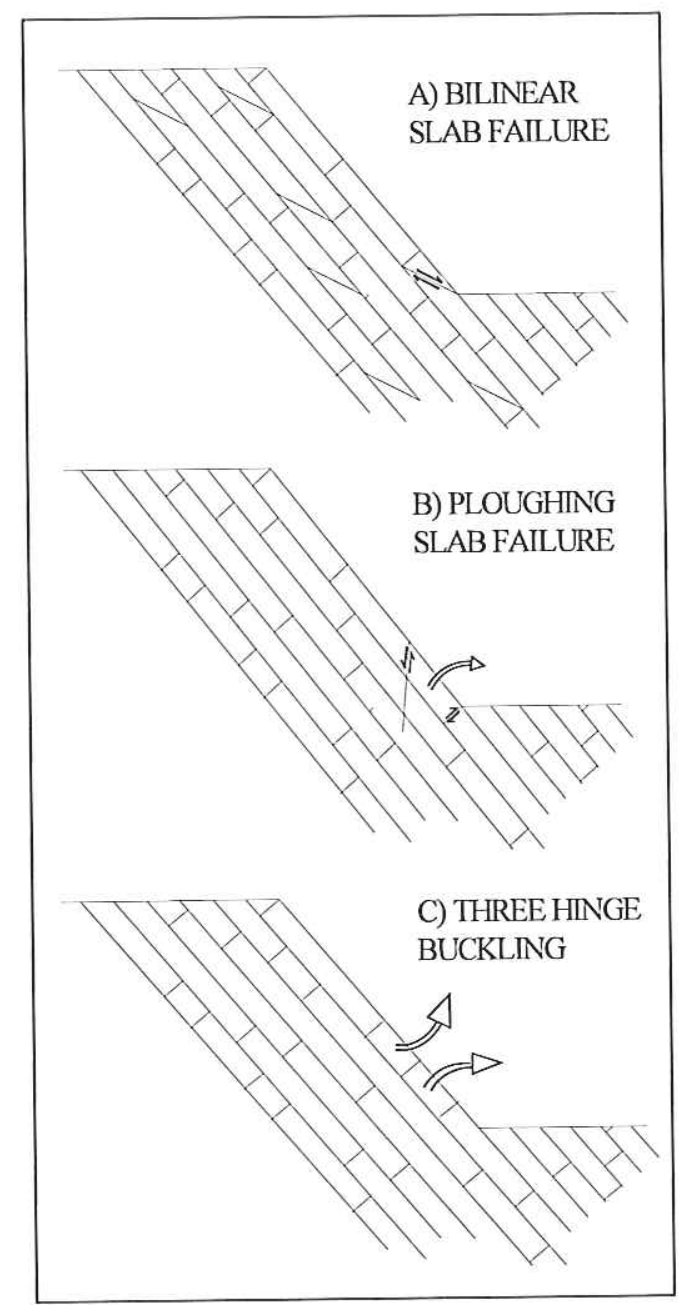

Figure 3. Totally discontinuity controlled failure mechanisms observed on footwall slopes, including A) Bilinear slab failure, B) Ploughing slab failure and C) Three hinge buckling.

There are other cinematically possible failure modes but they have not been reported or observed as far as the author is concerned. Remark also that due to the complex geometrical nature of strata, e.g. rolls, folding and so on, some apparently complex mechanisms can be included in one of the groups of the presented classification, as it can be the case of step-path failures.

\subsection{Partially joint controlled failure mechanisms}

The three basic mechanisms of this type analogous to those fully controlled by discontinuities are:

a) Bilinear slab failure with shearing and/or crushing in the toe of the slope, similar to the one all along discontinuities, but with the failure of the rock mass penetrating through the slope toe. The authors have observed this mechanism in road slopes excavated in flysch rocks in northern Spain and Alejano et al (2001) also reported such a mechanism in a quarry. 
b) Ploughing slab failure, with shearing of the rock mass in the slope face and shearing or tensile separation in the toe of the slope. Coulthard et al (2004) described a slope failure in a coal mine in Australia falling within this type of mechanisms.

c) Euler buckling of the first rock bed as presented by Cavers (1981).

The geometries of these failures are much likely those of full discontinuity control shown in Figure 3, and they are presented in Figure 4.

Due to the higher strength of the rock mass versus the rock joints, these mechanisms tend to be less common and more difficult to identify than the previously presented ones, but they should not be a priori discarded in a design analysis.
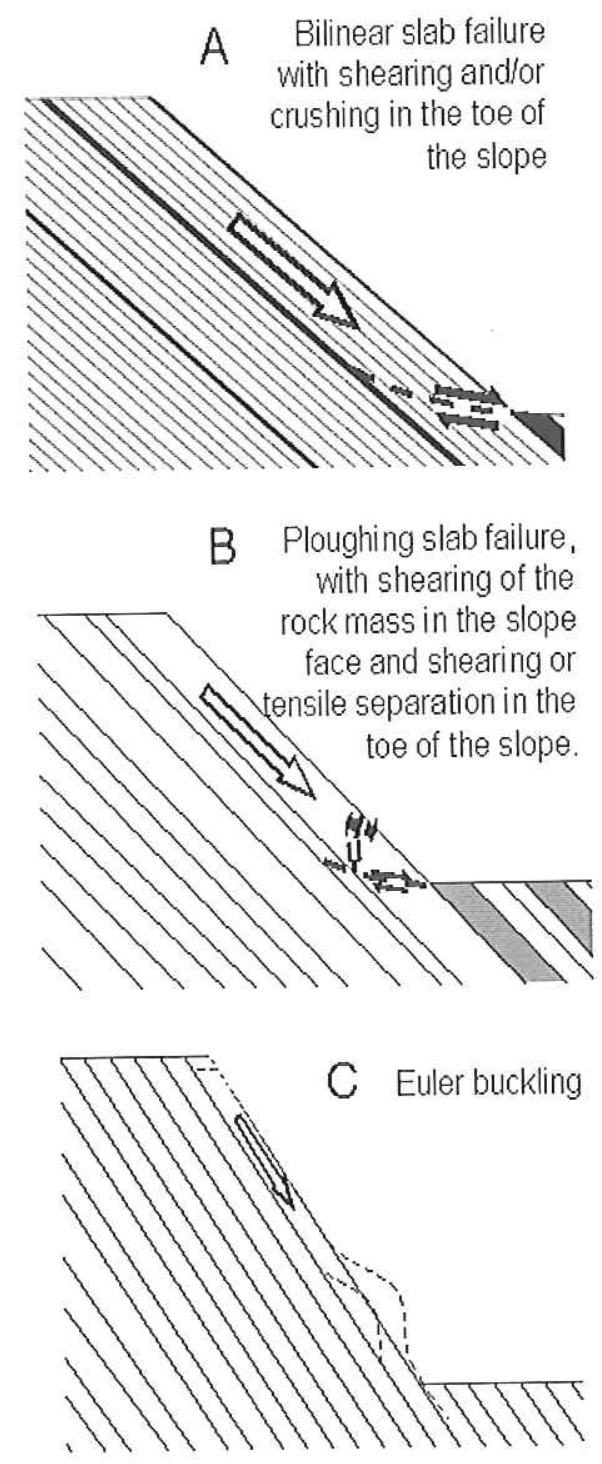

Figure 4. Partially discontinuity controlled failure mechanisms observed on footwall slopes, including A) Bilinear slab failure with shearing, B) Ploughing slab failure with shearing and tensile failure and C) Euler buckling. 


\section{LIMIT EQUILIBRIUM METHOD APPROACH}

LEM are based on the force and moment equilibrium in a rock mass or in different sliding or toppling blocks in a mass. The method may require some more or less realistic assumptions to be made. The degree of realism of these hypotheses determines the reliability of the results obtained. If, as in the case of fully discontinuity controlled cases, failure is due to movements of blocks full limited by geological discontinuities, the geometry and joint shear strength are the key parameters in the analyses and, when no untrue assumptions are taken, LEM are accurate enough to obtain reliable results.

Three-hinge and Euler buckling are not studied in what follows. The authors refer to the work of Cavers (1981) for a detailed approach to study these mechanisms.

\subsection{Discontinuity controlled bilinear slab failure}

The stability analysis is done dividing the sliding elements into an active block (1) or slab and a passive block (2) in the toe (Figure 5). For the sake of simplicity, the calculations that follow assume null cohesion joints and no underground water.

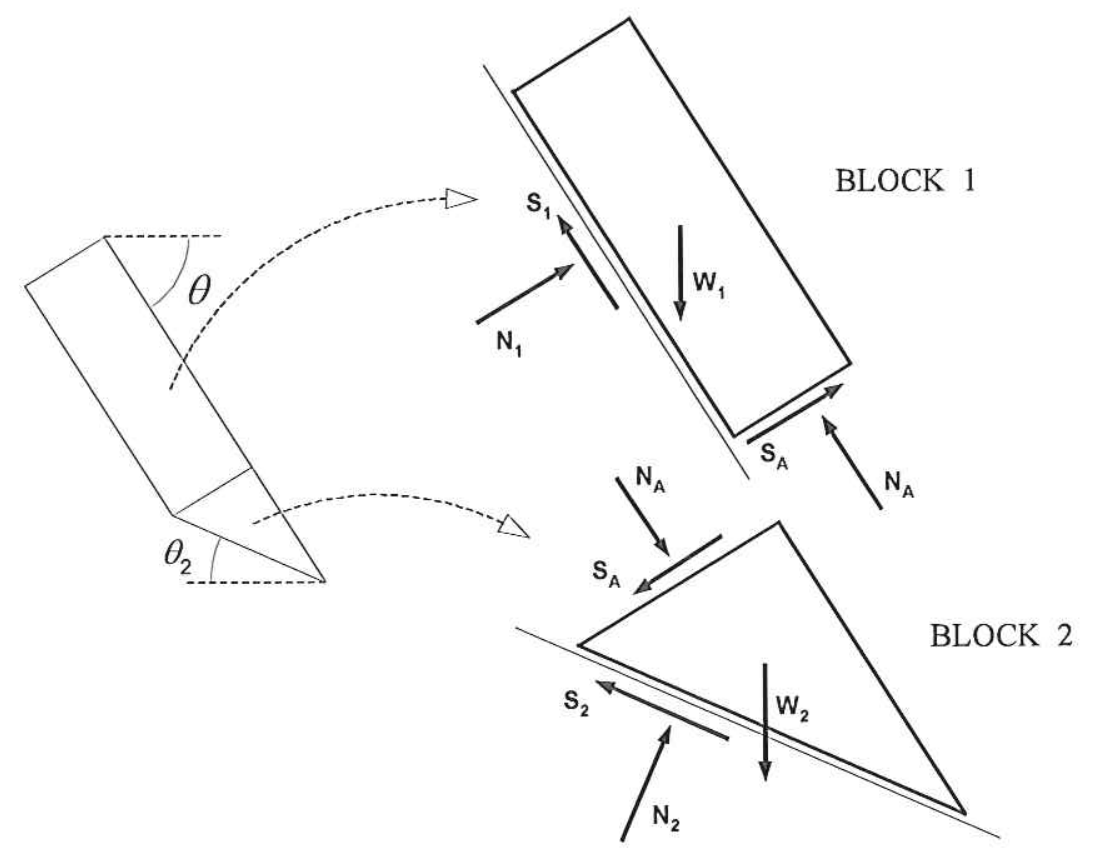

Figure 5. Bilinear slab failure analysis geometry.

First, the normal external force needed by the active block to be stable $\left(\mathrm{N}_{\mathrm{A}}\right)$ is calculated, and then, this force is transferred to the resisting block to calculate the safety factor. The analysis needs an assumption concerning the state of the interface between the active and the resisting blocks. If we assume that this boundary is frictionless, it can be found that: 


$$
\begin{gathered}
N_{A}=W_{1}\left[\sin (\theta)-\cos (\theta) \cdot \tan \left(\phi_{1}\right)\right] \\
F o S=\frac{\left[W_{2} \cos \left(\theta_{2}\right)+N_{A} \sin \left(\theta-\theta_{2}\right)\right] \tan \left(\phi_{2}\right)}{W_{2} \sin \left(\theta_{2}\right)+N_{A} \cos \left(\theta-\theta_{2}\right)}
\end{gathered}
$$

If we assume that there is friction acting on this interface, and that the upper block is in limit equilibrium, it can be found that:

$$
\begin{gathered}
N_{A}=\frac{W_{1}\left[\sin (\theta)-\cos (\theta) \tan \left(\phi_{1}\right)\right]}{1-\tan \left(\phi_{A}\right) \tan \left(\phi_{1}\right)} \\
F o S=\frac{\left[W_{2} \cos \left(\theta_{2}\right)+N_{A}\left[\sin \left(\theta-\theta_{2}\right)+\cos \left(\theta-\theta_{2}\right) \tan \left(\phi_{A}\right)\right]\right] \tan \left(\phi_{2}\right)}{W_{2} \sin \left(\theta_{2}\right)+N_{A}\left[\cos \left(\theta-\theta_{2}\right)-\sin \left(\theta-\theta_{2}\right) \tan \left(\phi_{A}\right)\right]}
\end{gathered}
$$

The realism of these assumptions varies according to the case, so no one can be considered a priori better. However, the actual value of the factor of safety has to be one in-between the values obtained according to the presented hypothesis. According to our experience, we suggest for practice the use of the average value safety factor (frictionless and friction assumptions).

\subsection{Discontinuity controlled ploughing slab failure}

The method of analysis is similar to the bilinear slab failure (see Figure 6). But in this case two further topics should be considered in greater detail.

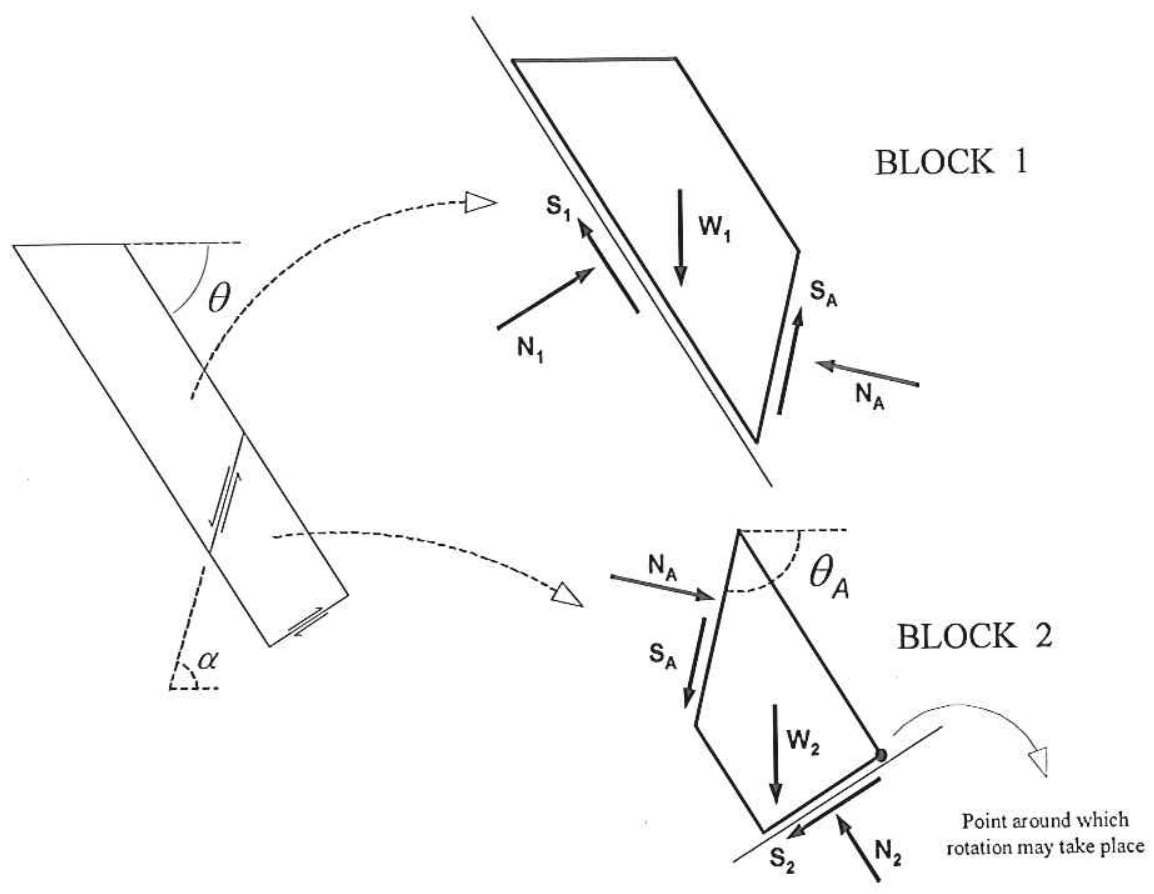

Figure 6. Ploughing slab failure analysis geometry. 
First, the only cinematically available possibility for the resisting block to move involves that the interface in-between blocks should be in limit equilibrium, so the second assumption proposed for the previous case should not only be used, but it is also a highly realistic one.

Second, the passive block may move out of the slope either sliding through the upper and lower limiting discontinuities or rotating freely out of the toe of the slope. It turns out then, that a different factor of safety should be computed for both types of mechanisms, finally selecting the smaller FoS, which will also mark the type of behaviour to be expected.

Assuming friction acting on the interface, we find:

$$
N_{A}=\frac{W_{1}\left[\sin (\theta)-\cos (\theta) \tan \left(\phi_{1}\right)\right]}{\sin \left(\theta_{A}-\theta\right)\left[1-\tan \left(\phi_{A}\right) \tan \left(\phi_{1}\right)\right]+\cos \left(\theta_{A}-\theta\right)\left[\tan \left(\phi_{1}\right)+\tan \left(\phi_{A}\right)\right]}
$$

The FoS for the sliding mode is calculated by:

$$
F o S=\frac{\left[N_{A}\left[\sin \left(\theta_{A}-\theta\right)+\cos \left(\theta_{A}-\theta\right) \tan \left(\phi_{A}\right)\right]+W_{2} \sin (\theta)\right] \tan \left(\phi_{2}\right)}{N_{A}\left[\cos \left(\theta_{A}-\theta\right)-\sin \left(\theta_{A}-\theta\right) \tan \left(\phi_{A}\right)\right]-W_{2} \cos (\theta)}
$$

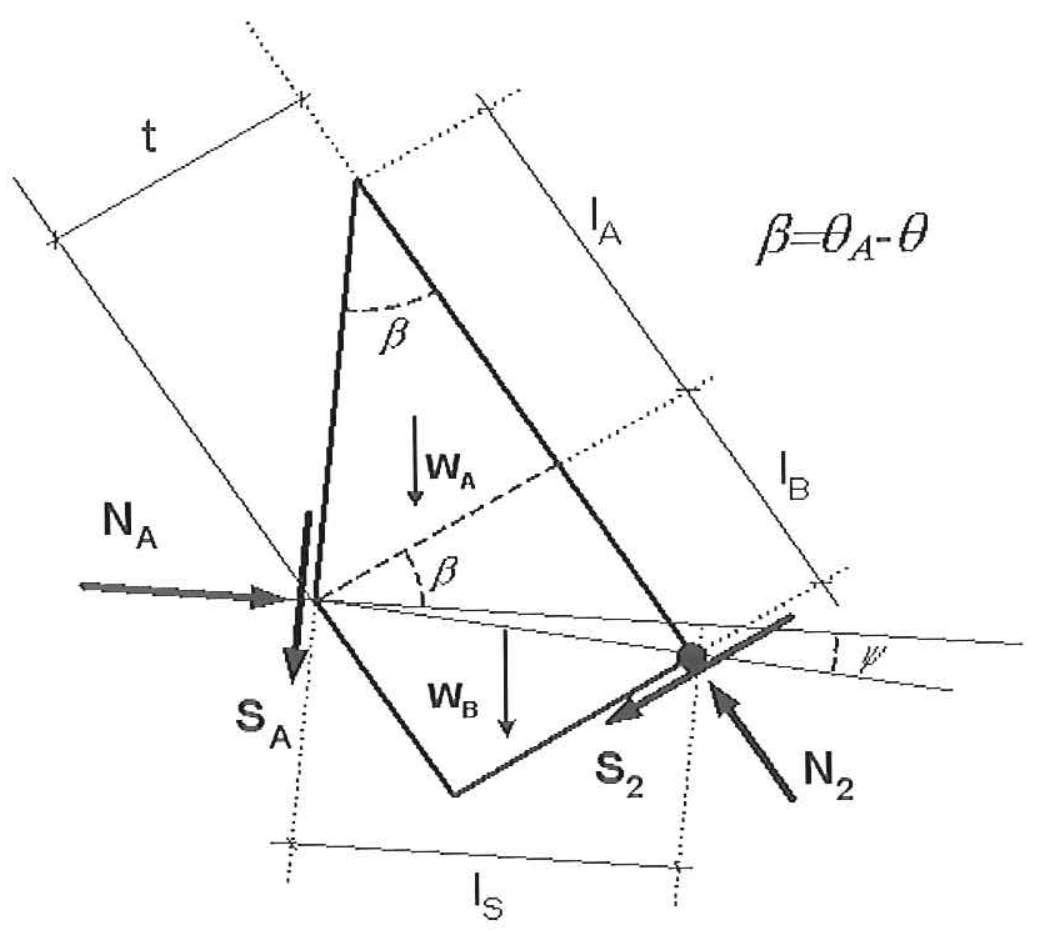

Figure 7. Detail of the passive block or wedge for the toppling analysis.

For the limit equilibrium of the toppling case, some geometric values are needed, which are defined in Figure 7. Finally, the FoS for the toppling mode is: 


$$
F o S=\frac{N_{A} \tan \left(\phi_{A}\right) l_{S}+W_{A}\left[\left(\frac{l_{A}}{3}+l_{B}\right) \cos (\theta)+\frac{t}{3} \sin (\theta)\right]+W_{B}\left[\left(\frac{l_{B}}{2}\right) \cos (\theta)+\frac{t}{2} \sin (\theta)\right]}{N_{A} l_{S} \tan (\psi)}
$$

Where:

$\psi=\left[\arctan \left(\frac{l_{B}}{t}\right)\right]-\left(\theta_{A}-\theta\right) ; \quad l_{S}=\left(\sqrt{l_{B}^{2}+t^{2}}\right) \cos (\psi) \quad \& \quad l_{A}=\frac{t}{\tan \left(\theta_{A}-\theta\right)}$

\subsection{Partially joint controlled failure mechanisms (bilinear and ploughing slab failure)}

Partially joint controlled mechanisms can be also analyzed by LEM. In particular, a specific geometric model is proposed which can simulate indistinctly bilinear and ploughing slab failure modes by varying three input geometric parameters.

The variable input parameters are called $\theta_{2}, \theta_{3}$ and $d$, which are defined in Figure 8. One can see that if $\theta_{3}=d=0$, then a bilinear slab failure mode appears; whereas if $\theta_{2}=$ $\theta_{1}-90, \theta_{3}>0$ and $d>0$, then a ploughing slab failure mode type results.

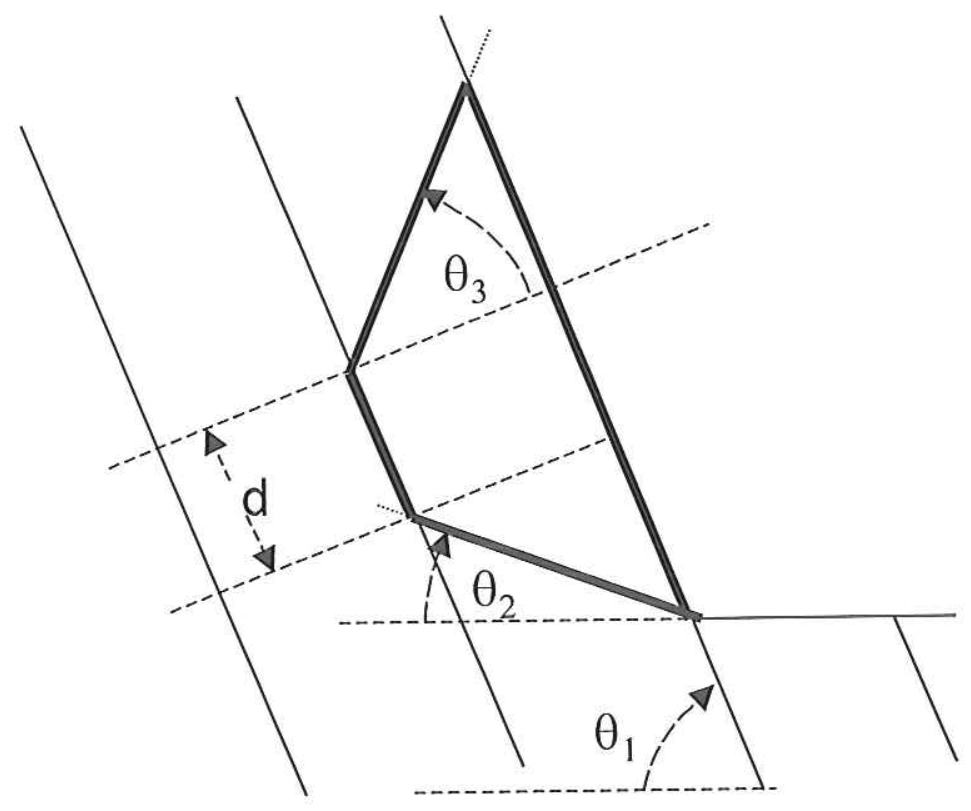

Figure 8. Geometric model to analyze partially discontinuity controlled failure mechanisms.

In both cases now, the joints to allow the model to be formed should appear by shearing or tensioning the rock mass. Since the sliding surfaces are not a priori known, these three parameters should be varied in order to minimize the FoS. The more realistic FoS obtained is the minimum calculated.

Also now, the two limiting joints are supposed to have the strength parameters of the intact rock mass including friction, $\phi_{r}$, and cohesion, $c_{r}$, which in these potential sliding 
planes have to be considered. The friction of the basal plane is now named $\phi_{j}$. Under these circumstances, the normal force exerted by the upper block in the lower one, assuming that there is friction acting on the interface, is:

$$
N_{A}=\frac{W_{1} \cdot\left(\sin \theta_{1}-\cos \theta_{1} \cdot \tan \phi_{j}\right)+c_{r} \cdot I_{2} \cdot\left(\cos \theta_{3} \cdot \tan \phi_{j} \cdot \sin \theta_{3}\right)}{\left[\sin \theta_{3} \cdot\left(\tan \phi_{j}+\tan \phi_{r}\right)\right]+\left[\cos \theta_{3}\left(1-\tan \phi_{j} \cdot \tan \phi_{r}\right)\right]}
$$

And the FoS for the sliding mode results:

$$
\text { FoS }=\frac{c_{r} \cdot l_{1}+\left[\mathrm{W}_{2} \cdot \cos \theta_{2}+\mathrm{N}_{\mathrm{A}} \cdot\left(\left(\tan \phi_{r}+c_{r} \cdot l_{2}\right) \cdot \cos \left(\theta_{1}-\theta_{2}-\theta_{3}\right)+\sin \left(\theta_{1}-\theta_{2}-\theta_{3}\right)\right)\right] \cdot \tan \phi_{r}}{\mathrm{~W}_{2} \cdot \sin \theta_{2}+\mathrm{N}_{\mathrm{A}} \cdot \cos \left(\theta_{1}-\theta_{2}-\theta_{3}\right)-\left[\left(\mathrm{c}_{\mathrm{r}} \cdot \mathrm{l}_{2}+\mathrm{N}_{\mathrm{A}} \cdot \tan \phi_{\mathrm{r}}\right) \cdot \sin \left(\theta_{1}-\theta_{2}-\theta_{3}\right)\right]}
$$

where $I_{1}=t / \sin \left(\theta_{1}-\theta_{2}\right)$ and $I_{2}=t / \cos \left(\theta_{3}\right)$, being $t$ the spacing of the bedding planes.

Note that in al the FoS calculation presented, it is possible to include cohesion in any plane, water pressures and anchor forces in order to perform a site-specific design. These topics are not accounted for in this study for the sake of simplicity.

\section{NUMERICAL MODELLING APPROACH}

\subsection{Methodology}

We have analysed different problems with different footwall slope failure mechanisms. A factor of safety (FoS) can be estimated for these mechanisms according to limit equilibrium methods (LEM). This FOS can also be calculated according to the shear strength reduction technique (SSRT) and by means of numerical models. For the failure modes where discontinuities play a significant role, it is very appropriate the use of distinct element codes such as UDEC (Itasca, 2004).

A numerical model simulates reality as it is. In this way, if one models a slope, either it is stable or it fails. Therefore, in order to obtain a FoS with numerical models, we need to use special techniques, such as the SSRT. This technique estimates the factors of safety (FOS) by performing a series of models with different tentative values of the FOS. These tentative values are used to reduce the actual values of the strength properties of the rock and joints (cohesion, friction, tensile strength), until the instability of the slope is observed. The final value of the FOS according to the SSRT is that corresponding to a limiting state (equilibrium-instability).

\subsection{Calculation examples and comparison to LEM}

To deepen the understanding on these mechanisms some theoretical examples are analysed according to LEM and numerical model (UDEC) and the SSRT. Another goal is to contrast these techniques and highlight their advantages and back draws. The first 
five examples concern totally joint controlled mechanisms -for which only rigid blocks are needed-, the last one includes partial joint control.

\subsubsection{Example 1. Bilinear slab failure}

The analysis focuses on a $50 \mathrm{~m}$ slope, dipping $50^{\circ}\left(\theta=50^{\circ}\right)$, formed by $3 \mathrm{~m}$ strata $(\mathrm{t}=3$ $\mathrm{m})$, and with a joint striking parallel to the slope in its toe and dipping $\theta_{2}=30^{\circ}$. The example includes another joint normal to bedding and located as shown in Figure 5 . The friction angle of bedding is $\phi_{1}=30^{\circ}$ and that of the other joints is $\phi_{A}=\phi_{2}=40^{\circ}$. The specific weight for examples 1 to 5 is.$=25 \mathrm{kN} / \mathrm{m}^{3}$. Under these circumstances and applying LEM and UDEC \& SSRT, the results are shown in Table 1. A graph representing the evolution of blocks is shown in Figure 9.a.

It can be checked that in the interface there is not only normal force-frictionless model-, but also shear one which is smaller than that needed to produce the movement of blocks along this interface-friction LEM-. Then it seems, that even if a shear force appears, it is smaller than that needed for limit equilibrium, so the FoS will be smaller than that obtained for that case, but larger than the frictionless one. The factors of safety obtained by means of UDEC-SRRT are usually not far from the average (frictionfrictionless) LEM value.

In order to analyse if the position of the joint normal to bedding plays a significant role in the stability, a new model named example $1 . b$ has been run. The only difference with the previously analysed case is that this joint normal to bedding and separating the two blocks has moved $5 \mathrm{~m}$ upwards in the direction of bedding. The rest of parameters are equal. The results are also similar as shown in Figure 9.b and table 1. This indicates that the position of this normal joint does not significantly affects results.

\subsubsection{Example 2. Ploughing slab failure (sliding)}

The analysis studies a $25 \mathrm{~m}$ slope, dipping $50^{\circ}\left(\theta=50^{\circ}\right)$, formed by $1.5 \mathrm{~m}$ strata $(\mathrm{t}=1.5 \mathrm{~m})$, and with a joint striking parallel to the slope in its toe and dipping towards the slope with $\theta_{A}=95^{\circ}$, according to Figure 6 . There is also a joint normal to bedding passing through the slope toe. For bedding planes $\phi_{1}=30^{\circ}$ and for the rest of the joints $\phi_{A}=\phi_{2}$ $=20^{\circ}$. The distance so called $l_{B}$ in Figure 7 is $l_{B}=2.293 \mathrm{~m}$. The numerical results are illustrated in Figure 9.c.

The results are shown in Table 1. A lower value of the FoS is obtained for the sliding case than for the toppling case. This can be read in terms of the mechanism of instability, which should be sliding. Also the in the analysis with UDEC and the SSRT a sliding mechanism is observed. However the accurateness of the obtained figures is not very good. 
Table 1. Factors of safety for the proposed examples $1,2 \& 3$.

\begin{tabular}{cllc}
\hline $\begin{array}{c}\text { Example \& } \\
\text { mechanism. }\end{array}$ & (LEM) & (eq.) & $\begin{array}{c}\text { UDEC - } \\
\text { SSRT }\end{array}$ \\
\hline $\begin{array}{c}\text { Example 1.a } \\
\text { Bilinear slab } \\
\text { with sliding }\end{array}$ & $\begin{array}{l}0.40 \text { (frictionless) } \\
1.45 \text { (friction) }\end{array}$ & $\begin{array}{l}(1 \& \text { \& }) \\
(3 \& 4)\end{array}$ & 1.028 \\
\hline $\begin{array}{c}\text { Example 1.a } \\
\text { Bilinear slab } \\
\text { with sliding }\end{array}$ & $\begin{array}{l}1.43 \text { (frictionless) } \\
0.94 \text { (average })\end{array}$ & $\begin{array}{l}(1 \& 2) \\
(3 \& 4)\end{array}$ & 1.034 \\
\hline $\begin{array}{c}\text { Example 2. } \\
\text { Ploughing slab } \\
\text { (sliding) }\end{array}$ & 1.76 (sliding) & $(5 \& 6)$ & 1.21 \\
\hline $\begin{array}{c}\text { Example 3. } \\
\text { Ploughing slab } \\
\text { (toppling) }\end{array}$ & 10.0 (sliding) & $\begin{array}{l}(5 \& 6) \\
(5,7 \& 8)\end{array}$ & 1.78 \\
\hline
\end{tabular}

\subsubsection{Example 3. Ploughing slab failure (toppling)}

The study focuses a $25 \mathrm{~m}$ slope, dipping $60^{\circ}\left(\theta=60^{\circ}\right)$, formed by $1.5 \mathrm{~m}$ beds $(\mathrm{t}=1.5 \mathrm{~m})$, and with a joint striking parallel to the slope in its toe and dipping towards it, with $\theta_{A}=95^{\circ}$. There is also a joint normal to bedding in the slope toe and $l_{B}=3 \mathrm{~m}$. The friction of bedding planes is $\phi_{1}=30^{\circ}$ and for the rest of the joints $\phi_{A}=\phi_{2}=40^{\circ}$. The numerical results are illustrated in Figure 9.d.

The results are shown in Table 1. In this case LEM and UDEC-SRRT compare well, for they both indicate toppling failure, but the FoS values are somewhat different (2.0 and $1.78)$ in this case.

One can be surprised at the differences in FoS obtained by both methods. In the case of example 1, this is due to the fact that neither the frictionless nor the friction assumptions are strictly correct. In examples 2 and 3, this can be due to the following. The LEM factor of safety compares two figures, one related to the forces or moments tending to stability and the other related to those tending to instability. Whereas the SSRT-UDEC factor of safety compares an estimate of the actual strength of the slope versus the strength needed to have the slope in limit equilibrium. Since the approaches are different, they must only coincide for the case of limit equilibrium $(\mathrm{FoS}=1,00)$ and they can diverge as long as the FoS is far from 1. FoS is not an actual variable, but it is an indicative value of the risk engineers are ready to assume. The following examples have been prepared to further investigate this topic.

\subsubsection{Examples 4 and 5. Ploughing slab failure.}

We analyse two examples, 4 and 5, representative of the failure mechanisms of ploughing slab failure, with sliding and toppling of the resisting block respectively. In both of them, the LEM FoS obtained is 1.00 , -that is to say- they are in limit equilibrium. The results of the analysis are shown in Table 2.

For the case of sliding (example 4) the safety factor obtained by UDEC and the SSRT is exactly 1.00 , demonstrating the accurateness of both methods to detect limit equilibrium. 
However, for the case of toppling (example 5), even if the FoS is close to one, it differs in 0.1 unities. This inaccurate result was surprising, so we investigated the possible reasons. We finally found out that this was due to the roundness of the corners of the UDEC blocks. The program selects a small value of this roundness automatically. When changing this value to a very small one $(\mathrm{r}=0.0005 \mathrm{~m})$, the FoS for toppling in example 5 became 0,9994 , and then, practically 1.00 . So it can now be stated that, when performing very detailed geometrical models and close to limit equilibrium, both techniques (LEM \& UDEC-SRRT), yield the same response.

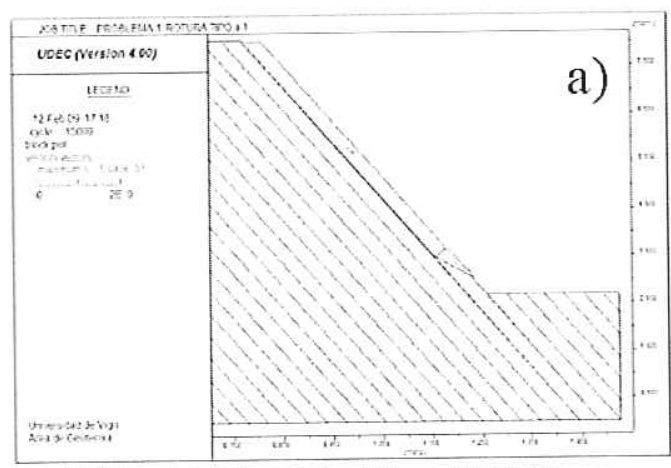

UDEC model of Example 1.a. Bilinear slab failure.

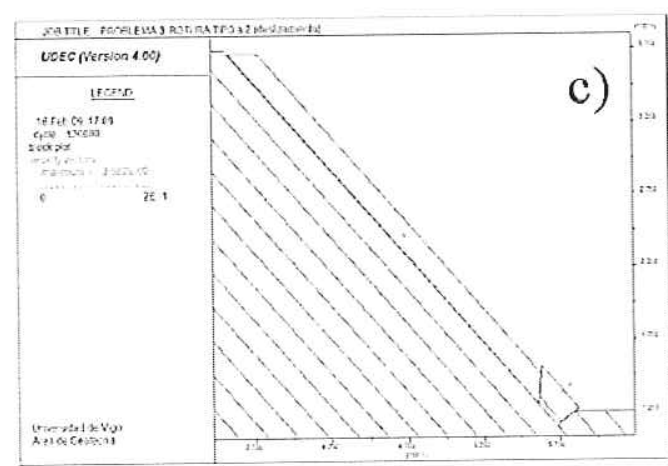

UDEC model of Example 2. Ploughing slab failure with sliding.

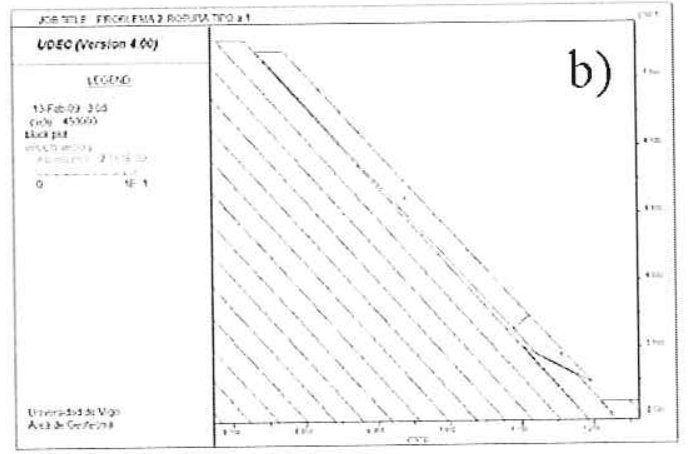

UDEC model of Example 1.b. Bilinear slab failure.

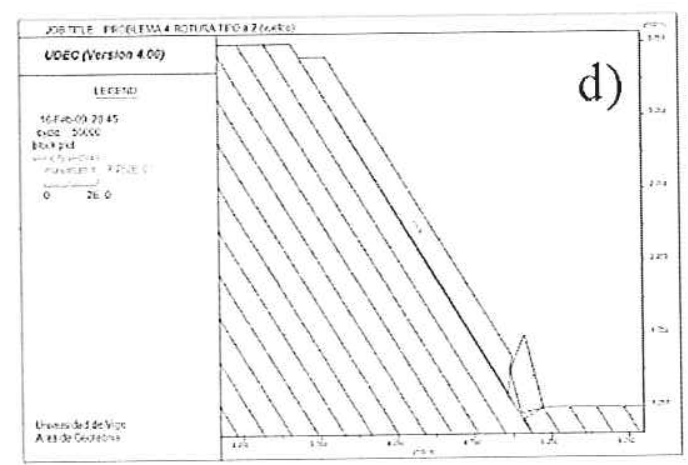

UDEC model of Example 3. Ploughing slab failure with toppling.

Figure 9. UDEC response of examples 1 to 4 , where the different mechanisms can be observed, the presented models correspond to the limit equilibrium case.

Table 2 . Factors of safety for the proposed examples $4 \& 5$.

\begin{tabular}{cllc}
\hline $\begin{array}{c}\text { Example \& } \\
\text { mechanism }\end{array}$ & (LEM) & (eq.) & $\begin{array}{l}\text { UDEC - } \\
\text { (SSRT) }\end{array}$ \\
\hline $\begin{array}{c}\text { Example 4. } \\
\text { Ploughing slab } \\
\text { failure (sliding) }\end{array}$ & $\begin{array}{l}1.00 \text { (for sliding) } \\
1.93 \text { (for toppling) }\end{array}$ & $\begin{array}{l}(5 \& 6) \\
(5,7 \& 8)\end{array}$ & 1.00 \\
\hline $\begin{array}{c}\text { Example 5. } \\
\text { Ploughing slab } \\
\text { failure (toppling) }\end{array}$ & 1.74 (for sliding) & $\begin{array}{l}(5 \& 6) \\
(5,7 \& 8)\end{array}$ & 0.90 \\
\hline $\begin{array}{c}\text { Example 5. } \\
\text { Ploughing slab } \\
\text { failure (toppling) } \\
\text { Roundness=0.0005 }\end{array}$ & 1,4 (for sliding) & $\begin{array}{l}(5 \& 6) \\
(5,7 \& 8)\end{array}$ & 0.9994 \\
\hline
\end{tabular}




\subsubsection{Example 6. Partially joint controlled footwall slope failure}

The analysis studies a $40 \mathrm{~m}$ slope, dipping $40^{\circ}\left(\theta=40^{\circ}\right)$, formed by $2 \mathrm{~m}$ strata $(t=2 \mathrm{~m})$. No other joints different from bedding are considered. The friction angle of bedding planes is $\phi_{j}=25^{\circ}$ and the strength of the rock in strata presents a $c_{r}=0.2 \mathrm{MPa}$ and $\phi_{r}=35^{\circ}$. A specific weight of $\gamma=28 \mathrm{kN} / \mathrm{m}^{3}$ is used.

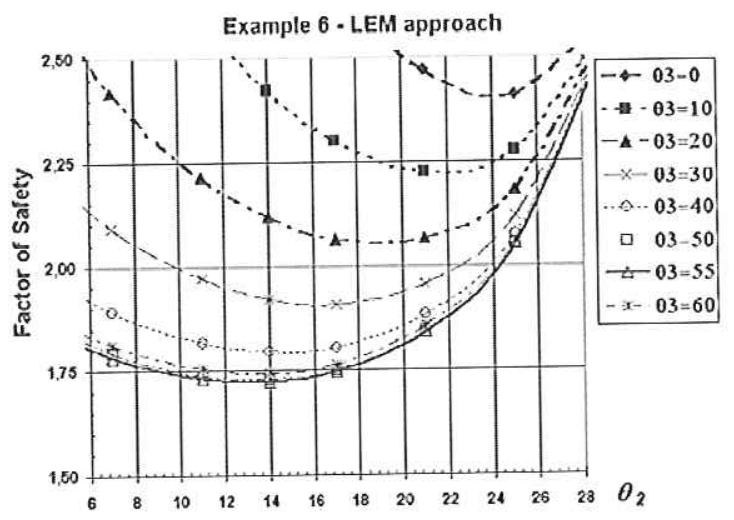

Figure 10. Graph showing the obtained FoS for the LEM defined (eq. $9 \& 10$ ) for different values of $\theta_{2}$ and $\theta_{3}$.

It is not that simple now the use of LEM, since we have to apply eq. $9 \& 10$ focusing on minimizing the FoS. These equations have been implemented in a calculation sheet and a minimum value of the $\mathrm{FoS}$ has been estimated in $\mathrm{FoS}=1.723$, corresponding to $\theta_{2}=14^{\circ}, \theta_{3}=55^{\circ}$ and $d=0$. A graph, showing the obtained $\mathrm{FoS}$ for different combinations of values of $\theta_{2}$ and $\theta_{3}$, for $d=0$, is presented in Figure 10 .

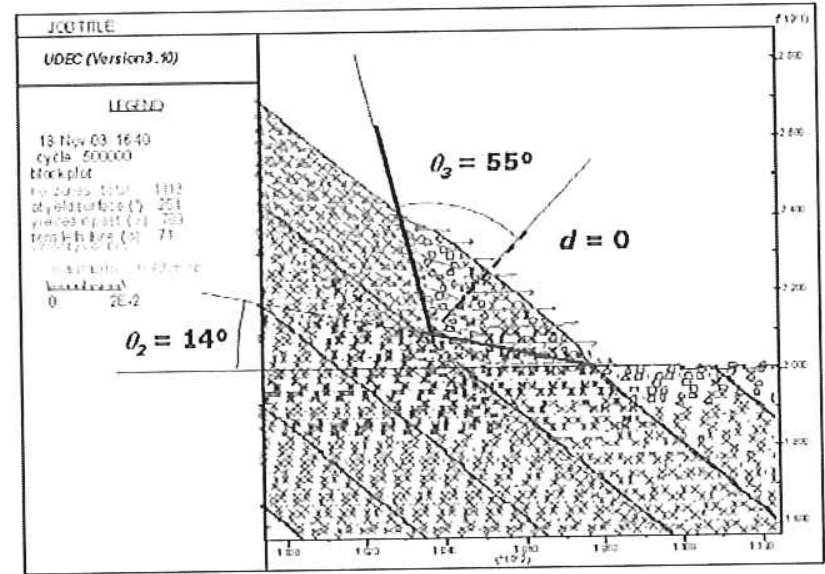

Figure 11. UDEC detail of partially discontinuity control failure mode with sliding of the resisting block.

The UDEC model, including deformable blocks for that case, found a value of the FoS between 1.6 and 1.7, somewhat smaller but very similar to the LEM one. The mechanism observed in UDEC compares sufficiently well with the one deduced from the LEM analysis, as Figure 11, illustrates. However, it should be indicated that when deformable blocks are used, the efficiency of the SSRT notably decreases. 


\section{PHYSICAL MODELLING}

As it has been observed, in the presented cases of footwall slopes analysed by means of LEM and of UDEC, together with SSRT; there are some open issues regarding for instance the use of friction or frictionless approach for the case of bilinear slab failure, or the influence of round corners in UDEC approach and in practice. In order to enlighten these topics and study in closer detail the bilinear slab and ploughing slab failure some simple physical models have been built, which in combination with a tilt test set-up, have permitted us to further analyse this type of foot-wall slope failure.

\subsection{Experimental set-up and model building}

To perform these physical models first small parallelepiped shaped granite slabs have been cut of dimensions (around $50 \mathrm{~mm} \times 50 \mathrm{~mm} \times 12 \mathrm{~mm}$ ). Some of these small slabs have been cut in parallel to their lateral sides and forming angles of around $30^{\circ}, 45^{\circ}$ and $60^{\circ}$ (Figure 12). In this way and due to the equal height of these slabs, different footwall slopes small models as in Figure 3 can be created and positioned on a tilt-test machine.

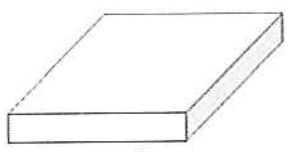

a)

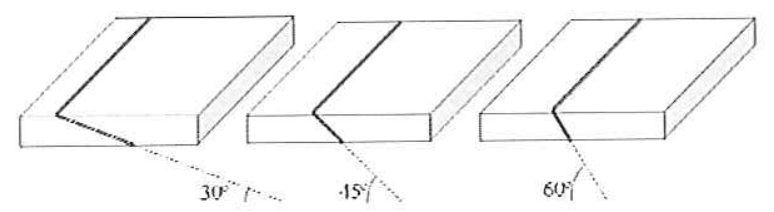

b)

c)

d)

Figure 12. Cutting of small granite slabs to create physical models.

The cut slabs have been rubbed among them in all his faces around one minute, so reasonably homogeneous roughness surfaces have been obtained. In this way more than twenty tilt tests performed with different slabs have yielded basic friction angles of $26,7^{\circ}$ in average with a standard deviation of less than $1^{\circ}$. The blocks sizes have been measured with a caliper, and also weighted to check that the volume multiplied by the density give the measured weight, with smaller than $1 \%$.

With such blocks, and preparing different configurations the footwall slopes failures presented in the previous section can be reproduced: namely discontinuity controlled bilinear and ploughing slab failures (Figure 13). In fact, the different configurations were prepared on the tilt test machine plane with a very mild angle. This plane was increasingly inclined up to the point where the instability takes place. These tests have been video recorded in order to correctly estimate the moment of the instability triggering. For this angle dip, a FoS equal to one was considered, and then the corresponding LEM and numerical approach were done to estimate the corresponding factors of safety following these methods, to compare it to the physical model approach. 


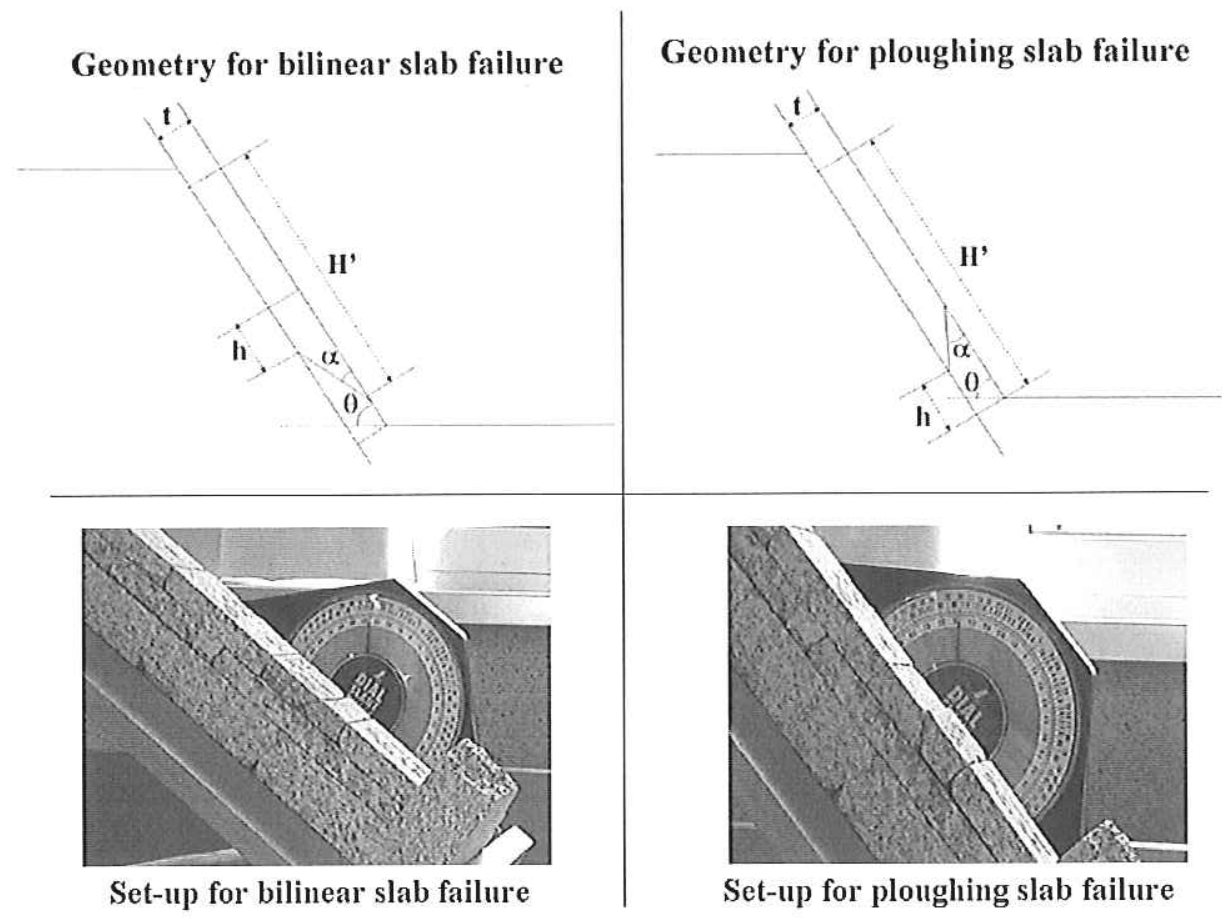

Figure 13. Geometry information and configuration of the footwall slopes physical models on a tilt-test set-up.

\subsection{Results}

For the first type of set-up to study bilinear slab failure various combination of the parameters presented in Figure $13\left(\alpha, \mathrm{h}\right.$ and $\left.\mathrm{H}^{\prime}\right)$, were prepared, and then, the plane was tilted until instability occurred for a particular value of $\theta$, as shown in table 3 . Detailed UDEC results, together with pictures of the sliding moment and estimates of factors of safety for this case are showed in Figures 14 and 15.

The same was done for some cases of ploughing slab failure where toppling was expected due to high value of $h$ prepared, as shown in table 4 . The corresponding figures with the information are shown in Figures 16 and 17.

And finally the same was done for some cases of ploughing slab failure where sliding was expected due to low value of $h$ prepared, as shown in table 5 . The corresponding figure, with all the relevant information of the different approaches, is presented in Figure 18.

Some of the tested cases did not show instability even when the tilt-plane was inclined close to $90^{\circ}$, so the results are not presented, but just indicated in tables 3 to 5 . 
Table 3. Geometrical input parameters for the physical models of bilinear slab failure and value of $\theta$, angle of observed instability.

\begin{tabular}{ccccccc}
\hline$\alpha\left({ }^{\circ}\right)$ & 29.05 & 29.05 & 46.22 & 46.22 & 60.82 & 60.82 \\
\hline $\mathrm{H}^{\prime}(\mathrm{m})$ & 0.2119 & 0.1322 & 0.1569 & 0.2063 & & \\
\hline $\mathrm{h}(\mathrm{m})$ & 0.0386 & 0.0083 & 0.0215 & 0.0215 & \\
\hline$\theta\left({ }^{\circ}\right)$ & $\mathbf{3 8}$ & $\mathbf{3 6}$ & $\mathbf{6 0}$ & $\mathbf{5 9}$ & STABLE $(>\mathbf{9 0})$ \\
\hline CASE NAME & $\mathrm{A} 1.1$ & $\mathrm{~A} 1.2$ & $\mathrm{~A} 1.3$ & $\mathrm{~A} 1.4$ & & \\
\hline
\end{tabular}

Table 4. Geometrical input parameters for the physical models of ploughing slab failure with toppling of the passive block and value of $\theta$, angle of observed instability.

\begin{tabular}{lcccccc}
\hline$\alpha\left(^{\circ}\right)$ & 29.05 & 29.05 & 46.22 & 46.22 & 60.82 & 60.82 \\
\hline $\mathrm{H}^{\prime}(\mathrm{m})$ & 0.2002 & 0.269 & 0.2701 & 0.2207 & & \\
\hline $\mathrm{h}(\mathrm{m})$ & 0.0494 & 0.0571 & 0.0638 & 0.0638 & \\
\hline$\theta\left(^{\circ}\right)$ & $\mathbf{5 5}$ & $\mathbf{4 6}$ & $\mathbf{6 3}$ & $\mathbf{6 5}$ & STABLE $\left(>\mathbf{9 0} 0^{\circ}\right)$ \\
\hline CASE NAME & $\mathrm{A} 22_{\mathrm{t}} .1$ & $\mathrm{~A} 2_{\mathrm{t}} \cdot 2$ & $\mathrm{~A} 2_{\mathrm{t}} .3$ & $\mathrm{~A} 2_{\mathrm{t}} .4$ & \\
\hline
\end{tabular}

Table 5. Geometrical input parameters for the physical models of ploughing slab failure with sliding of the passive block and value of $\theta$, angle of observed instability.

\begin{tabular}{|c|c|c|c|c|c|}
\hline$\alpha .\left(^{\circ}\right)$ & 29.05 & 29.05 & 46.22 & 60.82 & 60.82 \\
\hline $\mathrm{H}^{\prime}(\mathrm{m})$ & 0.2202 & 0.1708 & & & \\
\hline h (m) & 0.0083 & 0.0083 & & & \\
\hline$\theta\left({ }^{\circ}\right)$ & 60 & 53 & & STABLE $\left(>90^{\circ}\right)$ & \\
\hline CASE NAME & $\mathrm{A} 2{ }_{5} .1$ & $\mathrm{~A} 22_{\mathrm{s}} .2$ & & & \\
\hline
\end{tabular}

A1.1

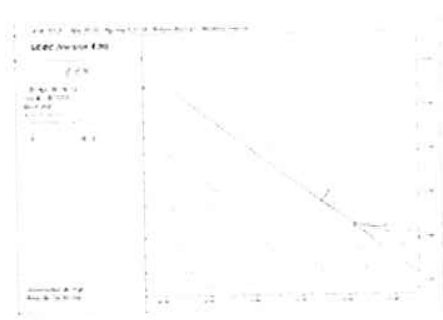

a)

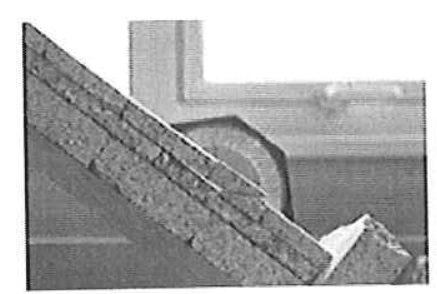

b)

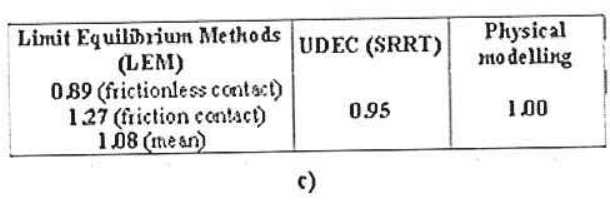

Al. 2

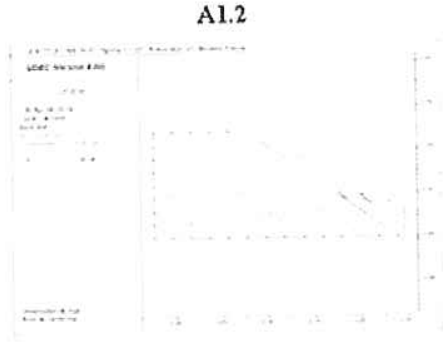

a)

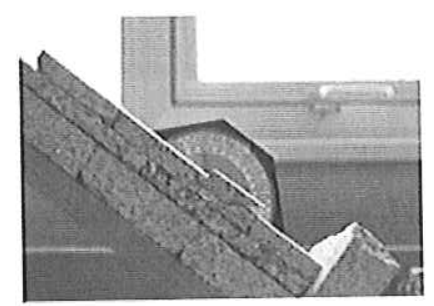

b)

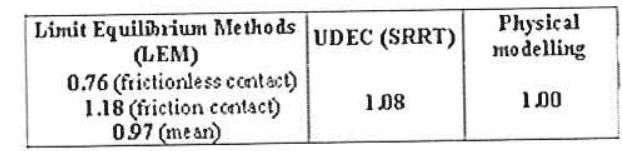

c)

Figure 14. Results of the a) UDEC numerical model, b) physical model and c) compilation of safety factor results for all the methods including LEM. Results for the case of bilinear slab failure for $\alpha$ roughly $30^{\circ}$. 
A1.3

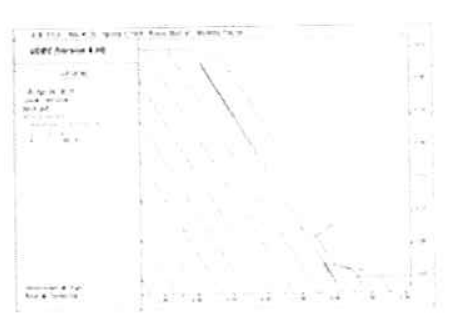

a)

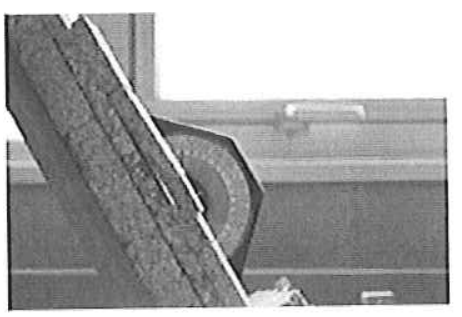

b)

\begin{tabular}{|c|c|c|}
\hline $\begin{array}{c}\text { Limit Equilihrium Methods } \\
\text { (LEM) }\end{array}$ & UDEC (SRRT) & $\begin{array}{c}\text { Physical } \\
\text { modelling }\end{array}$ \\
$\begin{array}{c}0.69 \text { (fictionless contset) } \\
1.70 \text { (friction contact) } \\
1.19 \text { (mean) }\end{array}$ & 1.18 & 100 \\
\hline
\end{tabular}

c)
Al.4

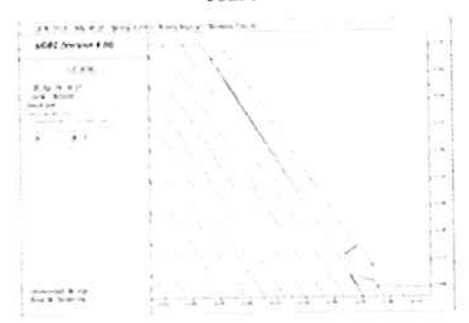

a)

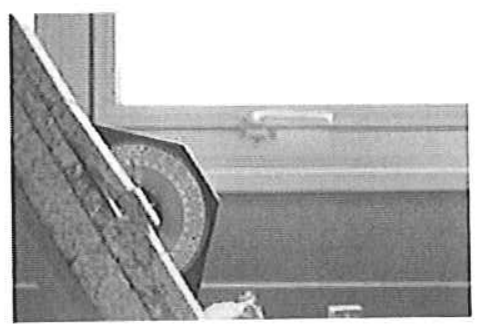

b)

\begin{tabular}{|c|c|c|}
\hline $\begin{array}{l}\text { Limit Equilihrium Methods } \\
\text { (LEM) }\end{array}$ & UDEC (SRRT) & $\begin{array}{l}\text { Physical } \\
\text { modelling }\end{array}$ \\
\hline $\begin{array}{c}0.66 \text { (frictionless contact) } \\
1.70 \text { (friction contact) } \\
1.18 \text { (mean) }\end{array}$ & 1.19 & 100 \\
\hline
\end{tabular}

c)

Figure 15. Results of the a) UDEC numerical model, b) physical model and c) compilation of safety factor results for all the methods including LEM. Results for the case of bilinear slab failure with $\alpha$ roughly $45^{\circ}$.

$\mathrm{A} 2.1$

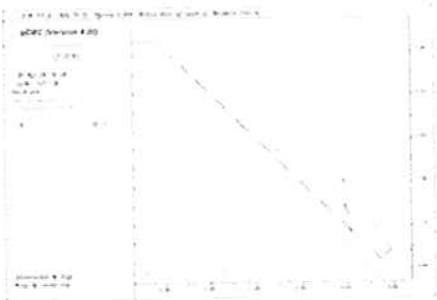

a)

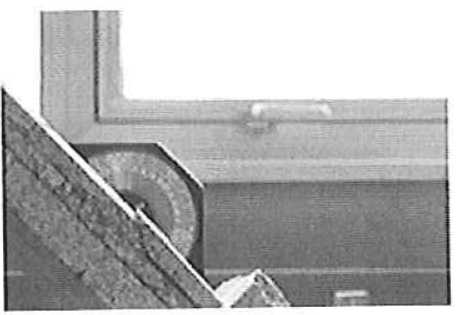

b)

\begin{tabular}{|c|c|c|}
\hline $\begin{array}{c}\text { Lintit Equilihrium Methods } \\
\text { (LEM) }\end{array}$ & UDEC (SRRT) & $\begin{array}{l}\text { Physical } \\
\text { modelling }\end{array}$ \\
\hline $\begin{array}{l}37.94 \text { (sliding) } \\
1.01 \text { (toppling) }\end{array}$ & 101 & 100 \\
\hline
\end{tabular}

c)
$\mathrm{A} 2,2$

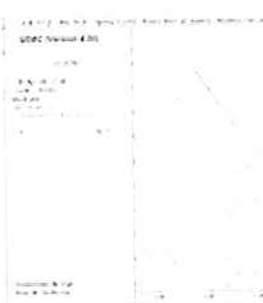

a)

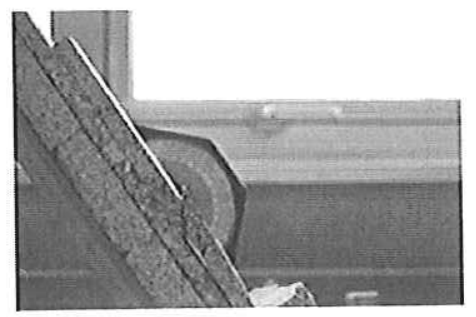

b)

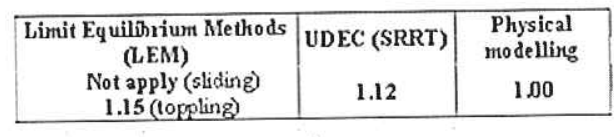

c)

Figure 16. Results of the a) UDEC numerical model, b) physical model and c) compilation of safety factor results for all the methods including LEM. Results for the case of ploughing slab failure with toppling for $\alpha$ roughly $30^{\circ}$. 
A2 3

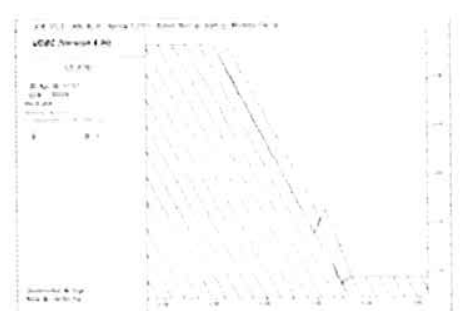

a)

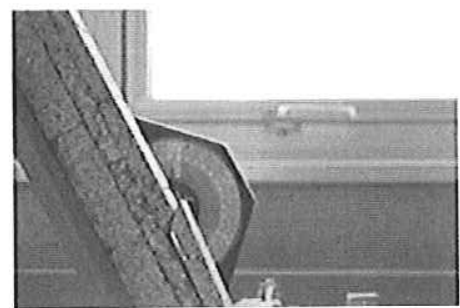

b)

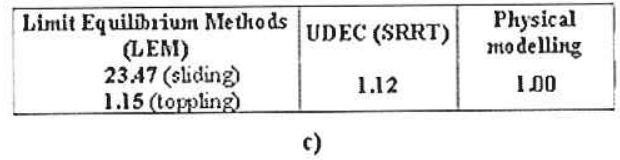

$\mathrm{A} 2+4$

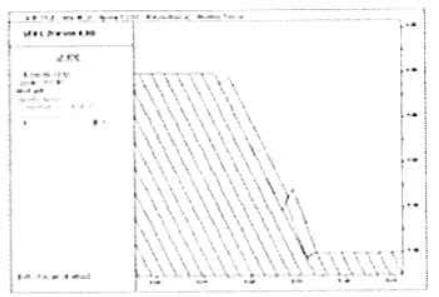

a)

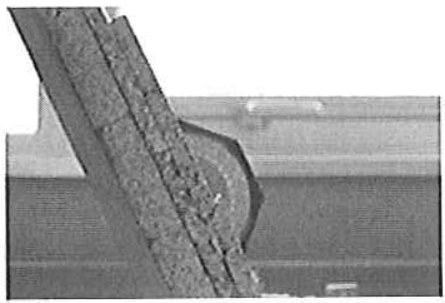

b)

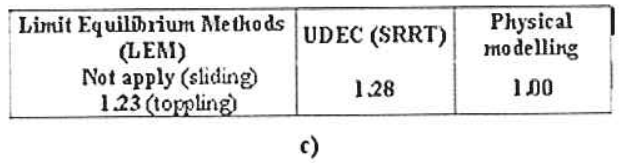

Figure 17. Results of the a) UDEC numerical model, b) physical model and c) compilation of safety factor results for all the methods including LEM. Results for the case of ploughing slab failure with toppling for $\alpha$ roughly $45^{\circ}$.

A2, 1

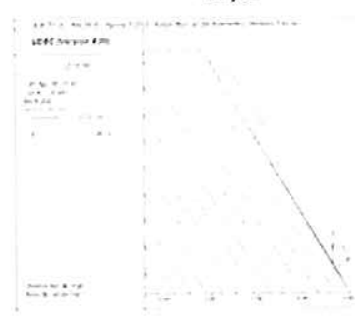

a)

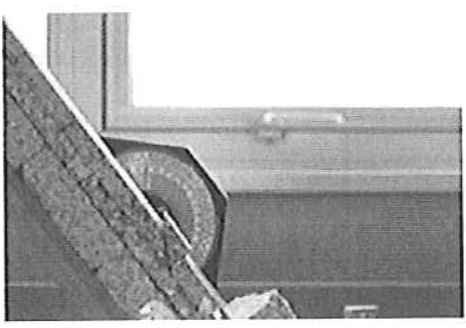

b)

\begin{tabular}{|c|c|c|}
\hline $\begin{array}{c}\text { Limit Equilihrium Mlethods } \\
\text { (LEM) } \\
103 \text { (sliding) } \\
6.39 \text { (togpling) }\end{array}$ & UDEC (SRRT) & $\begin{array}{c}\text { Physical } \\
\text { modelling }\end{array}$ \\
\hline
\end{tabular}

c)
A2, 2

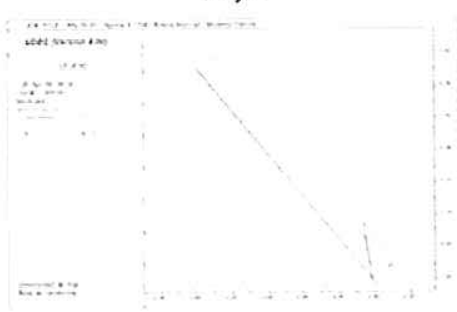

a)

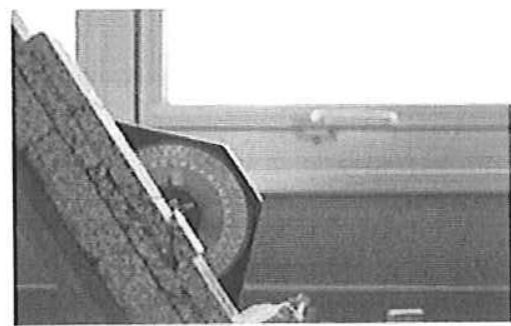

b)

\begin{tabular}{|c|c|c|}
\hline $\begin{array}{c}\text { Limit Equilihrium Methods } \\
\text { (LEM) } \\
134 \text { (stiding) } \\
737 \text { (toppling) }\end{array}$ & UDEC (SRRT) & $\begin{array}{c}\text { Physical } \\
\text { modelling }\end{array}$ \\
\hline
\end{tabular}

c)

Figure 18. Results of the a) UDEC numerical model, b) physical model and c) compilation of safety factor results for all the methods including LEM. Results for the case of ploughing slab failure with sliding with $\alpha$ roughly $30^{\circ}$. 
The final results can be summarized in the table 6 . As observed in this table, the factors of safety $(\mathrm{FoS})$, derived from LEM are in average $13 \%$ higher than those derived from the physical modelling. In a similar way, the factors of safety derived from the application of the shear strength reduction technique to the UDEC numerical approach are in average around $11 \%$ higher than those obtained from the physical modelling. This small error could be due to a decrease in the frictional response of joints in the lower part of the modelled slopes associated to a higher normal stress. It can also be due to the non-perfect normality of the slab boundaries, to the occurrence of non-perfect contacts between slabs as well as to the natural friction variability. However the observed differences are not much too high for a discipline, such as rock mechanics, where certain variability can be always expected. The observed inaccuracy let us suggest factors of safety in the range of 1.4 to 1.5 for the initial design of this type of slopes.

Table 6. Factors of Safety corresponding to the tested physical models.

\begin{tabular}{|c|c|c|c|}
\hline CASE & $\begin{array}{c}\text { Physical Models } \\
\text { FoS }=1 \text { (in all cases) }\end{array}$ & $\begin{array}{l}\text { Limit Equilibrium Methods } \\
\text { (LEM) FoS }\end{array}$ & $\begin{array}{c}\text { UDEC (SSRT) } \\
\text { FoS }\end{array}$ \\
\hline A1.1 & $\begin{array}{c}\alpha=29.05-\mathbf{H}^{\prime}=0.2119 \\
(\text { Foot wall Failure a1) }\end{array}$ & $\begin{array}{l}0.89 \text { (frictionless contact) } \\
1.27 \text { (friction contact) } \\
1.08 \text { (mean) }\end{array}$ & 0.95 \\
\hline A 1.2 & $\begin{array}{c}\alpha=29.05-H^{\prime}=0.1322 \\
\text { (Footwall Failure a1) }\end{array}$ & $\begin{array}{l}0.76 \text { (frictionless contact) } \\
1.18 \text { (friction contact) } \\
0.97 \text { (mean) }\end{array}$ & 1.08 \\
\hline A 1.3 & $\begin{array}{c}\alpha=46.22-H^{\prime}=0.1569 \\
\text { (Footwall Failure a1) }\end{array}$ & $\begin{array}{l}0.69 \text { (frictionless contact) } \\
1.70 \text { (friction contact) } \\
1.19 \text { (mean) }\end{array}$ & 1.18 \\
\hline A 1.4 & $\begin{array}{c}\alpha=46.22-\mathrm{H}^{\prime}=0.2063 \\
\text { (Footwall Failure a1) }\end{array}$ & $\begin{array}{l}0.66 \text { (frictionless contact) } \\
1.70 \text { (friction contact) } \\
1.18 \text { (mean) }\end{array}$ & 1.19 \\
\hline A2s. 1 & $\begin{array}{c}\alpha=29.05-\text { H'}^{\prime}=0.2202 \\
\text { (Footwall Failure a2) }\end{array}$ & $\begin{array}{l}1.03 \text { (for sliding) } \\
6.39 \text { (for toppling) }\end{array}$ & 1.01 \\
\hline A $2 \mathrm{~s} .2$ & $\begin{array}{c}\alpha=29.05-H^{\prime}=0.1708 \\
\text { (Footwall Failure a2) }\end{array}$ & $\begin{array}{l}1.34 \text { (for sliding) } \\
7.37 \text { (for toppling) }\end{array}$ & 1.12 \\
\hline A2t. 1 & $\begin{array}{c}\alpha=29.05-H^{\prime}=0.2202 \\
\text { (Footwall Failure a2) }\end{array}$ & $\begin{array}{l}37.94 \text { (for sliding) } \\
1.01 \text { (for toppling) }\end{array}$ & 1.01 \\
\hline A $2 \mathrm{t} .2$ & $\begin{array}{c}\alpha=29.05-H^{\prime}=0.269 \\
\text { (Footwall Failure a2) }\end{array}$ & $\begin{array}{l}\text { Not apply (for sliding) } \\
1.15 \text { (for toppling) }\end{array}$ & 1.12 \\
\hline A2t. 3 & $\begin{array}{c}\alpha=46.22-H^{\prime}=0.2701 \\
\text { (Footwall Failure a2) }\end{array}$ & $\begin{array}{l}23.47 \text { (for sliding) } \\
1.15 \text { (for toppling) }\end{array}$ & 1.18 \\
\hline A2t. 4 & $\begin{array}{c}\alpha=46.22-H^{\prime}=0.2207 \\
(\text { Footwall Failure a2) }\end{array}$ & $\begin{array}{l}\text { Not apply (for sliding) } \\
1.23 \text { (for toppling) }\end{array}$ & 1.28 \\
\hline
\end{tabular}




\section{CONCLUSIONS}

Footwall slope failure mechanisms have been reviewed and different techniques -LEM and the SSRT with code UDEC- to obtain factors of safety in these cases have been presented and applied to various examples and one case study. As a consequence of all this, the following considerations have been drawn.

LEM are a good choice to obtain FoS in those footwall slopes where the failure mechanism grants limit equilibrium in all blocks - ploughing slab failure with sliding or toppling of the resisting block-. For the case of bilinear failure slab results are not sufficiently good and more realistic assumptions are needed. For partially discontinuitycontrolled mechanisms LEM is a possible choice but the technique needs a careful and massive calculation in order to contemplate all possible failure modes.

LEM, if results are reliable, are preferred than SSRT in that it is easier to perform further-but commonly needed-analysis like parametric studies, back-analysis, statistical analysis like Monte Carlo and so on.

The combination of the SSRT with UDEC is a very strong technique to estimate FoS for every mechanism of footwall slope instability, having the advantages of finding automatic and naturally the failure mechanism and the critical slip or separation surfaces. It should be used within the frame of more wide design methodology as proposed by Starfield \& Cundall (1988). Nevertheless, this technique is more complex to use; making more difficult the carrying out of further studies.

Finally, a series of physical models with different arrangements of rock slabs, positioned on a tilt-test set-up have been performed. These models have demonstrated in practice the previously presented mechanisms and have also served to assess the degree of accuracy of the limit equilibrium and numerical approaches. For the studied cases the factors of safety of the LEM and UDEC-SSRT have resulted in values between 10 and $15 \%$ higher in average than those observed in the physical cases. Even though theses difference were not very high, it seems convenient to recommend using FoS in the range of 1.4 to 1.5 for actual slope design.

Future work contemplates the application of the proposed approaches to slope instability problems actually observed in practice taken from the literature and from author's experience.

\section{ACKNOWLEDGEMENTS}

The authors acknowledge local Government of Galicia (Consellería de Innovación e Industria de la Xunta de Galicia) the financing received to develop this research project under the title "Stability analysis of wall slopes", with reference number (INCITE08PXIB304076PR). The former students of the University of Vigo Abel Sánchez Juncal \& David Posada are thanked for their help in performing some tasks associated to the presented work. Ailish M.J. Maher provided assistance with English usage. 


\section{REFERENCES}

Alejano (2004): Footwall slope failure mechanisms and design considerations using UDEC. Proceedings of the 1st International UDEC/3DEC Symposium: numerical modelling of discrete materials in geotechnical engineering. Bochum (Germany). Balkema, Rótterdam, Holland.

Alejano, L.R.; García Bastante, F., Alonso, E. \& Gómez-Márquez, I. Stability analysis and design of two quarry slopes with the help of numerical modeling. EUROCK 2001, ISRM Symposium, Rock Mechanics a challenge for society. Espoo, Finland. Ed. Balkema. June, 2001.

Brawner, C.O., Pentz, D.L. and Sharp, J.C., 1971. Stability studies of a footwall slope in layered coal deposits. Proc. 13th US Symposium on Rock Mechanics, pp. 329365.

Calder, P.N.. And Blackwel, G.H.. Investigation of a complex rock displacement at Brenda Mines. The Canadian Mining and Metallurgy Bulletin. Pp. 1-10. August, 1980.

Cavers, D.S. 1981. Simple methods to analyze buckling of rock slopes. Rock Mech. \& Rock Eng. 14: 87104.

Coulthard, M.A., Lucas D.S. And Fuller, P.G. Application of UDEC to a stress-related mine slope failure al Leigh Creek, South Australia. Proceedings of the Symposium on Numerical Modelling of Discrete Materials, Bochum (Germany). Ed. Konietzky. Balkema. Pp. 289-296. October 2004.

Dawson, E.M., Roth, W.H. \& Drescher, A. 1999. Slope stability analysis by Strength reduction. Geotechnique. 49(6): 835-840.

Hawley P.M, Martin, D.C. \& Acott. C.P. 1985. Failure mechanics and design considerations for footwall slopes. 87th Ann. Gen. Meet. Can. Inst. of Min. \& Metall. Vancouver. 29 pp.

Hoek, E. \& Brown, E.T. 1997. Practical estimates of rock mass strength. Int. Journal of Rock Mech. Sci. \& Geom. Abstr. 34 (8): 1165-1187.

Hoek, E., Bray, J., 1974. Rock Slope Engineering. IMM. Chapman \& Hall. London, UK.

Itasca. 2000. User manual for UDEC, Version 3.1. Itasca Consulting Group Inc., Minnesota, USA.

Kliche, Ch.A., 1999. Rock Slope Stability. S.M.E. Society for Mining, Metallurgy and Exploration, Inc. Littleton, Co., USA.

Manera Bassa, C.; Ramírez Oyanguren, P. Rotura en dos bloques de los taludes de muro de explotaciones de carbón". Boletín Geológico y Minero. Volumen 99.(261-266), 1986.

Ramírez Oyanguren, P. \& Alejano, L.R. 1992. Numerical and Analytical stability analysis of footwall slopes in opencast coal mines. Geotech. Meet.. Santiago de Chile (Chile).

Starfield. A.M. \& Cundall, P.A. 1988. Towards a methodology for rock mechanics modeling. Int. Journal of Rock Mech. Sci. \& Geom. Abstr. 25(3): 99-106.

Stead, D., Eberhardt, E.: Developments in the analysis of footwall slopes in surface coal mining. Engineering Geology 46 (1997) 4161.

Stimpson, B. and Robinson, K.E., 1982. A computer program for footwall slope stability analysis in steeply dipping bedded deposits. 3rd Conference on Stability in Surface Mining, pp. 437-455.

Walton, G. and Atkinson, T., 1978. Some geotechnical considerations in the planning of surface coal mines. Trans. Sect. A. Inst. Mining Metal., 87: 147-171. 